\title{
Review
}

\section{Ten Years Evidence-based High-Tech Acupuncture-A Short Review of Centrally Measured Effects* (Part II)}

\section{Gerhard Litscher}

Research Unit of Biomedical Engineering in Anesthesia and Intensive Care Medicine, Medical University of Graz, Auenbruggerplatz 29, A-8036 Graz/Austria

\begin{abstract}
The assessment of acupuncture-induced effects on brain function is crucial. Ultrasound-assisted brain function monitoring and bioelectrical methods as well as near infrared spectroscopic procedures and functional magnetic resonance investigations form the basis for the latest scientific examination methods for acupuncture research. The laserneedle acupuncture, which was examined scientifically for the first time in Graz, represents a new painless and noninvasive acupuncture method. In this way, individual combinations of acupuncture points can be stimulated simultaneously according to traditional Chinese medicine. In the context of double-blind studies, effects in the brain could be demonstrated in a reproducible manner for the first time. This second part of the short review article summarizes some of the centrally measured effects of acupuncture obtained at the Medical University of Graz within the last 10 years.
\end{abstract}

Keywords: complementary medicine-integrative medicine-laserneedle acupuncturetraditional Chinese medicine

\section{Introduction}

Using needle, laserneedle or electrical stimulation and modern biomedical techniques, changes in peripheral and cerebral activities can be quantified (1-8). This second part of the review lecture deals with central effects of acupuncture. The methods used therefore can be seen in Fig. 1, right panel.

Similar to the first part of the review article, in all investigations described in this article, the test persons were informed about the procedure and gave their consent and were not under the influence of medication

For reprints and all Correspondence: Gerhard Litscher, Research Unit of Biomedical Engineering in Anesthesia and Intensive Care Medicine, Medical University of Graz, Auenbruggerplatz 29, A-8036 Graz/

Austria. Tel: + 43316 385-3907; Fax: + 43316 385-3908;

E-mail: gerhard.litscher@meduni-graz.at

*This article was presented by the author in part as a keynote lecture at the 10th East-West Medical CMIR Conference 'Integrative MedicineThe Future?' on March 17, 2007, at the Royal College of Physicians in London. This article is based on the review series 'Bioengineering Assessment of Acupuncture' as published in 'Critical Reviews in Biomedical Engineering' $(1-5,37)$ at the time of measurement. The studies were approved by the Ethics Committee of the Medical University of Graz.

\section{Multidirectional Transcranial Ultrasound Doppler Sonography (TCD)}

Cerebral blood flow velocity can be registered with compact ultrasound systems using the Doppler principle. Transmission frequencies usually lie between 1 and $20 \mathrm{MHz}$ in vascular diagnostics or during monitoring (9). Low frequencies have a high penetration depth but low sonic reflection of blood cells, whereas high transmission frequencies have a lower penetration depth but better sonic reflection (10). Ultrasound waves are mechanic, matter-bound density waves with frequencies of $>20 \mathrm{KHz}$. These are produced by electric alternating voltage being applied to piezoelectric crystals ('transducer'). The waves propagate in biologic tissue (with the exception of bone) at a nearly constant speed $\left(\sim 1550 \mathrm{~m} \mathrm{~s}^{-1}\right)(11)$. The waves are totally or partially 


\section{Acupuncture}

Computer-based quantification

\begin{tabular}{|c|c|c|c|c|}
\hline Needle & $\Leftrightarrow$ & Laserneedle & $\Leftrightarrow$ & Electroacupuncture \\
\hline \multicolumn{3}{|c|}{$\begin{array}{l}\text { Peripheral } \\
\text { effects }\end{array}$} & & $\begin{array}{c}\text { Central } \\
\text { effects }\end{array}$ \\
\hline \multicolumn{3}{|c|}{$\begin{array}{l}\text { Thermography } \\
\text { (Surface temperature) }\end{array}$} & & $\begin{array}{l}\text { Multidirectional } \\
\text { transcranial ultrasound } \\
\text { Doppler sonography (TCD) } \\
\text { (Blood flow velocity) }\end{array}$ \\
\hline \multicolumn{3}{|c|}{$\begin{array}{l}\text { Laser Doppler } \\
\text { flowmetry (LDF) } \\
\text { (Microcirculation) }\end{array}$} & & $\begin{array}{l}\text { Regional cerebral near- } \\
\text { infrared spectroscopy (NIRS) } \\
\text { (Changes of oxygen metabolism) }\end{array}$ \\
\hline \multicolumn{3}{|c|}{$\begin{array}{l}\text { Laser Doppler } \\
\text { imaging (LDI) }\end{array}$} & & $\begin{array}{l}\text { Functional magnetic } \\
\text { resonance imaging (fMRI) }\end{array}$ \\
\hline+ Standari & parametc & & & $\begin{array}{l}\text { Bioelectrical methods } \\
\text { (EEG, BSS, tatropy }\end{array}$ \\
\hline
\end{tabular}

Figure 1. High-tech biomedical methods for computer-controlled quantification of peripheral (first part of this review article) and cerebral effects of acupuncture.

reflected and weakened by scattering and absorption at biologic-acoustic border regions. Ultrasound waves of low intensity $\left(<10 \mathrm{~mW} \mathrm{~cm}^{-2}\right.$; diagnostics) are considered to be harmless (11).

For intracranial TCD vascular monitoring, spectrum analysis is generally required due to the weak reflection of Doppler signals. A pulse curve above the zero line shows the course of blood flow to the probe in basal cerebral arteries, whereas the opposite is usually true for extracranial vessels. This curve was selected for reasons of definition, since the important intracranial vessel, the middle cerebral artery (MCA), shows the direction to the temporally applied ultrasound probe.

Branches of the MCA can usually be investigated at a depth of $3-4 \mathrm{~cm}$, the media main trunk usually lies at a depth of $5.5-6.5 \mathrm{~cm}$. Blood flow velocity in the internal carotid artery (distal part at a depth of $60-65 \mathrm{~mm}$ ) as well as in the MCA can be determined by transtemporal entry. With increasing depth of measurement volumina, a part belonging to the anterior cerebral artery (ACA) can be also determined. If the ultrasound probe is turned slightly in the dorsal and caudal direction, the origin of the posterior cerebral artery (PCA) can be reached at a depth of $65-75 \mathrm{~mm}$.

Registration of blood flow profiles in the ophthalmic artery (OA) was performed with a probe, applied lateral to the cornea on the closed bulb of the eye. Reduction in transmission energy should be achieved as far as possible, in order to avoid direct exposure to sonic waves of the lens (12). A signal from the OA is registered at a depth of $40-50 \mathrm{~mm}$ by a probe turned slightly in the central direction.

The foramen magnum offers a further path of entry for ultrasound measurements. Dependent upon anatomical variations, the basilar artery (BA) lies at a depth between

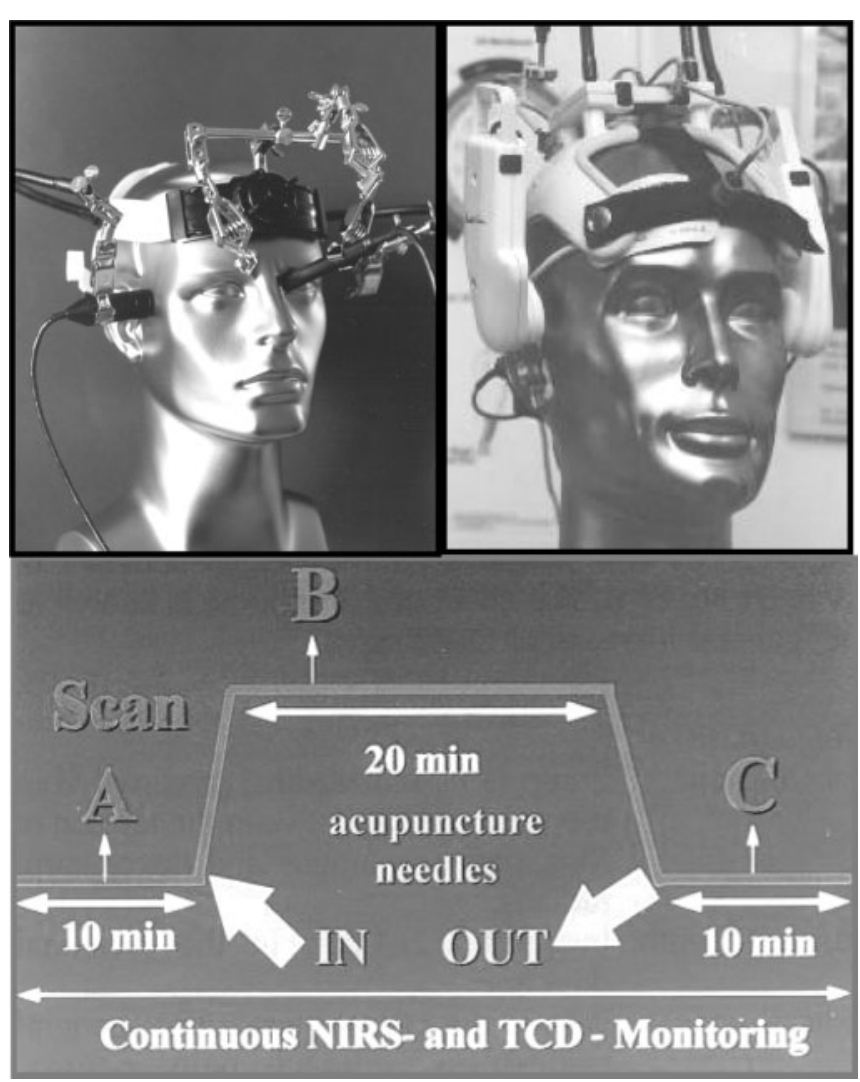

Figure 2. High-tech helmet constructions for measuring cerebral effects of acupuncture. Measuring procedure (A, before; $\mathbf{B}$, during and $\mathbf{C}$ after acupuncture). Modified from (20).

70 and $110 \mathrm{~mm}$ (12). The vertebral artery (VA) and the BA show blood flow directed away from the probe (3).

Here, we would like to note that several new developments in this field of research regarding the probe holder construction have been made, which can be applied in scientific studies with acupuncture specific monitoring (Fig. 2).

These new constructions have made it possible to perform simultaneous and continuous measurements of blood flow velocity in several larger vessels (e.g. MCA and OA) (13-15). Figure 2 (right upper panel) shows the construction (16) with which simultaneous and continuous flow profiles can be determined at eight different depths and represents the scientific instrument used in our first guiding acupuncture study performed in 1997 (17).

In the following, changes in TCD parameters under the influence of acupuncture in healthy volunteers are presented. Transcranial Doppler sonography was performed with three instruments (Multi Dop T, Multi Dop X4 and Smart Dop by DWL Electronic Systems GmbH, Sipplingen, Germany). We used 2 and $4 \mathrm{MHz}$ probes applied with a new set-up and computer-controlled probes, which were integrated in a probe holder device (Fig. 2, left upper panel). 


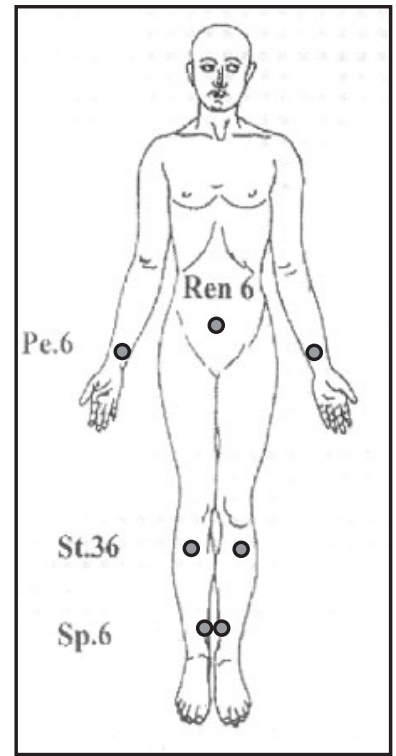

Unspecific invariable acupuncture scheme

Neiguan

Qihai

Zusanli

Sanyinjiao

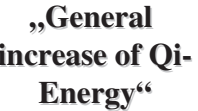

Figure 3. The acupuncture pattern consisted of points that-according to TCM-lead to a general increase of Qi energy in the brain. Modified from (20).

In addition to measuring blood flow velocity in the MCA, ACA, PCA, BA and VA, transorbital registrations were also performed. Here, the smallest intensity was used that yielded assessable signals (maximum $20 \mathrm{~mW} \mathrm{~cm}-2$ ). Flow profiles of the supratrochlear artery (STA), the inner end branch of the OA, were measured transorbitally. This vessel is considerably constant and isolated and can be localized without directly exposing the bulbus to ultrasonic waves (18).

Monitoring of the STA was performed by applying an ultrasound probe with a special holder to the medial corner of the eye in a slightly medial and parietal direction and without pressure. The angle and position of the probe was altered under acoustic control until the largest possible signal amplitude could be achieved. In addition, alterations in flow velocities in the MCA were determined simultaneously and continuously in several studies.

Mean blood flow velocity $\left(v_{\mathrm{m}}\right)$ has proved to be an important parameter. Figure 2 schematically shows the measurement profile and phases of evaluation of the first published studies done by our research group (17,19-21). The acupoints used in these studies are shown in Fig. 3. Figure 4 shows a typical result of a significant increase of mean blood flow velocity in the MCA during manual needle acupuncture stimulation $(17,20,21)$.

Altogether, a total of 12 volunteers (mean age: $35.2 \pm 4.4$ years; $26-41$ years) were examined using this first acupuncture-specific transcranial sonographic study $(17,20,21)$. Four test persons were female, eight were male. The test subjects were positioned, relaxed on a bed before starting the procedure. Then the TCD measurement setup was positioned. After a 10 min resting period,



Figure 4. The blood flow profiles changed during and after acupuncture. The blood flow velocity increased on average by about $13 \%$. Modified from (17).

an unspecific, constant acupuncture scheme was selected for all 12 test persons (Fig. 3). According to traditional Chinese medicine (TCM), this acupuncture scheme mobilizes the 'general supply of energy'. In order to increase these possible effects, the needle at acupoint Qihai (Ren 6, CV 6) was additionally treated with moxibustion for $3 \mathrm{~min}$.

The single acupoints were located using a point selecter (Pointoselect plus by Schwa-Medico, Gießen, Germany). After exact localization, the acupoints were punctured in a vertical and deep manner with single use needles. Acupuncture-specific De-Qi sensations were triggered in each case. The needles remained in place for $20 \mathrm{~min}$ without any further stimulation. After removing the needles, a concluding phase of 10 further minutes followed.

Data were evaluated with analysis of variance (one-way repeated-measure ANOVA) before, during, and after acupuncture. The TCD measurement data in this study were evaluated with $v_{\mathrm{m}}$ in the right MCA. In addition, post hoc analysis (Tukey test) was performed (SigmaStat and SigmaPlot, Jandel Scientific Corp., Erkrath, Germany).

The results from the TCD parameters $10 \mathrm{~min}$ before, during (measuring time: $2 \mathrm{~min}$ after applying the needles) and $10 \mathrm{~min}$ after acupuncture showed a significant $\left(P<0.01\right.$; Tukey test) difference in $v_{\mathrm{m}}$ during acupuncture compared to the phase before acupuncture. It is also interesting that the flow velocities during the control period after acupuncture yield higher values than prior to investigation (17,19-21).

In a cross-over study design, 13 healthy volunteers aged between 24 and 63 years (mean age \pm SD: $39.5 \pm 13.5$ 


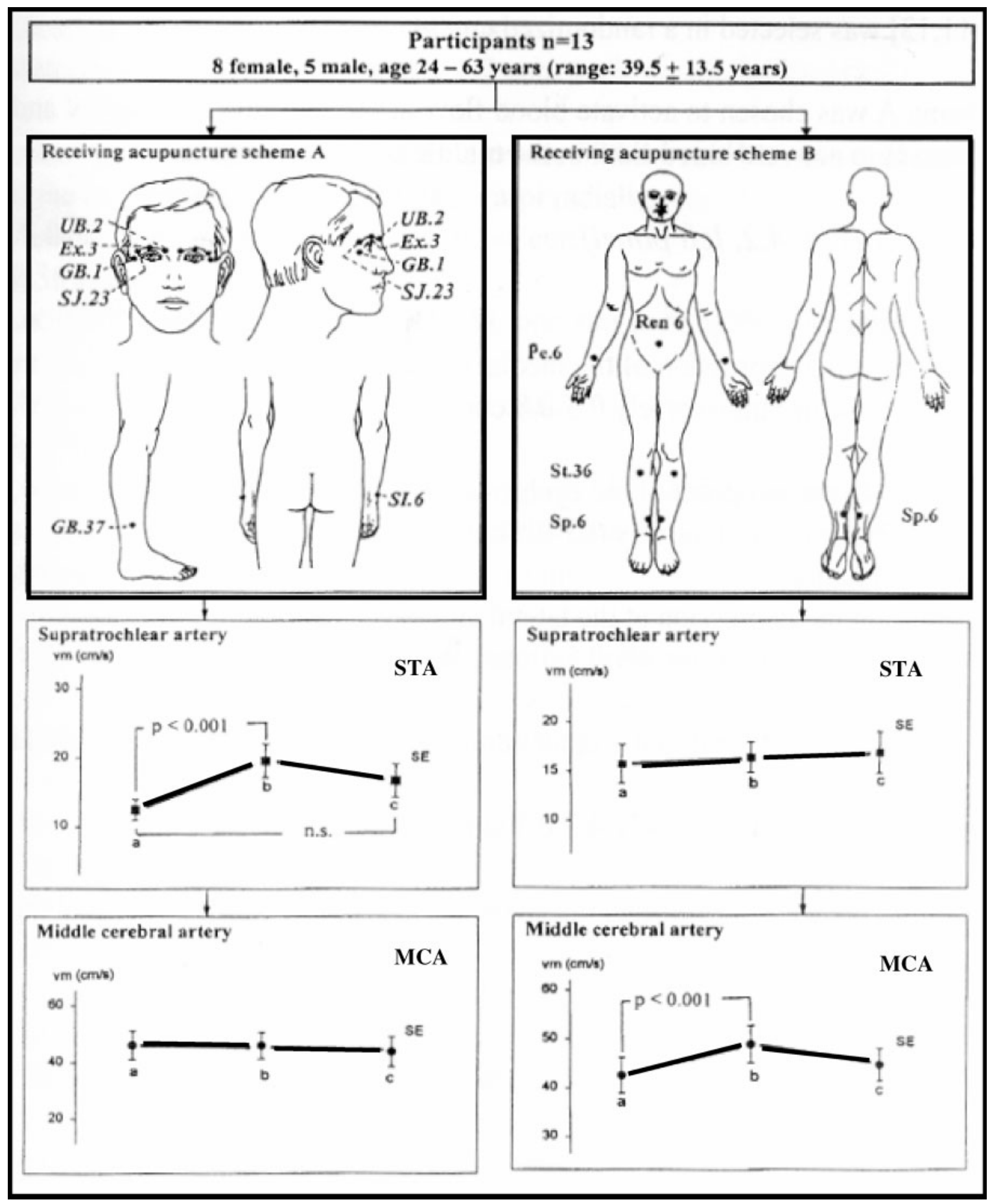

Figure 5. A cross-over study carried out on healthy volunteers is of particular significance. In the process, needles were inserted into the same test subject - once in the eye acupuncture pattern (A) and once with the pattern that increases the blood flow velocity in the middle cerebral artery (B). In the first examination with the eye pattern (left panels), the blood flow velocity increased in the STA, and in the other examination (right panels) it increased in the MCA. Modified from (22).

years) were examined (22). Different acupuncture schemes and testing conditions were used on the same test person (Fig. 5).

When using the optic scheme (Fig. 5A) a significant increase in blood flow velocity in the STA occurred, whereas the flow velocity in the MCA remained nearly unchanged. In reverse, scheme $\mathrm{B}$ led to a significant increase in flow velocity in the MCA with nearly unchanged flow profile patterns in the STA. Several cross-over studies were performed and confirmed the initial results of selective changes in cerebral perfusion after acupuncture $(3,6-8,15,19)$. This meant that placebo 
trials could be avoided to a certain degree. The technique and study designs demonstrated that acupuncture produces specific and reproducible effects on the brain and eye but cannot explain the underlying mechanism (22).

In a further study, 27 healthy volunteers, (14 females, 13 males) with a mean age of $25.2 \pm 4.1(\overline{\mathrm{x}} \pm \mathrm{SD})$ years (21-38 years) were examined (23). Seven eye-specific acupoints were tested on all volunteers in two different measurement series [laserneedle acupuncture (see part I of this review article) and needle acupuncture]. The acupuncture scheme consisted of two acupoints according to TCM: Zanzhu (UB.2; location: at the medial end of the eyebrow, vertically above the inner corner of the eye at the foramen of the supraorbital nerve. Needling: vertical 0.5-0.8 cun) and Yuyao (Ex.3; location: at the middle of the eyebrow vertically above the pupil; needling: oblique $0.3-0.5$ cun). In addition, two ear acupoints (eye and liver: needling: oblique $0.3 \mathrm{cun}$ ), two eye-specific Korean hand acupuncture points (E2: needling: vertical $0.1-0.2$ cun) and one acupoint from Chinese hand acupuncture (Yan Dian: location: at the ulnar side of the middle joint of the thumb; needling: oblique 0.2 cun) were stimulated (24-26). The different acupuncture methods were combined, since preliminary studies showed that the selection of these points led to increased effects in the measured cerebral parameters $(15,19)$.

Three different types of needles (body: $0.25 \times 25 \mathrm{~mm}$, Huan Qiu, Suzhou, China; ear: $0.2 \times 13 \mathrm{~mm}$, European Marco Polo Comp., Albi, France; hand: $0.1 \times 8 \mathrm{~mm}$, Sooji-Chim, Korea) were used. Stimulation was done with simultaneous rotating and thrusting movements of medium intensity.

A $10 \mathrm{~min}$ resting period was taken after applying the monitoring sensors. Then, either laserneedle stimulation was activated or acupuncture needles were inserted and stimulated for $20 \mathrm{~s}$. Thereafter, all lasers were either activated for $10 \mathrm{~min}$ or the inserted needles remained untouched in all test persons. The maximum amplitude of $v_{\mathrm{m}}$ was used for analysis at this time. Two minutes after deactivation or removal of the needles a further control measurement was performed. Selection of which method was to be performed first was randomized. Each test person underwent laserneedle acupuncture as well as needle acupuncture. The resting time between each single examination was $20-30 \mathrm{~min}$.

The results yielded a significant increase in $v_{\mathrm{m}}$ in the OA during laserneedle acupuncture $(P=0.01)$ and needle acupuncture $(P<0.001)$. At the same time, nonsignificant changes in $v_{\mathrm{m}}$ in the MCA were evident. Mean arterial blood pressure did not change significantly during laserneedle acupuncture or needle acupuncture. The maximum amplitude of $v_{\mathrm{m}}$ was achieved in the OA with a time shift of $10-30 \mathrm{~s}$ after the initial stimulus in needle acupuncture was set, and with a delay of $20-60 \mathrm{~s}$ after starting laser stimulation.

\section{Regional Cerebral Near-Infrared Spectroscopy (NIRS)}

Because of its non-invasive approach the NIRS method allows the evaluation of cerebral oxygenation through the intact skull and is of great in importance in acupuncture research (5).

Different instrumental components are used in acupuncture research (27). One system applied in the field of research is the NIRO 300 (Hamamatsu Photonics, Hamamatsu, Japan). In addition to the already known parameters including changes in oxyhemoglobin $\left(\Delta \mathrm{O}_{2} \mathrm{Hb}\right)$, deoxyhemoglobin $(\Delta \mathrm{HHb})$, complete hemoglobin $\left(\Delta \mathrm{cHb}=\Delta \mathrm{O}_{2} \mathrm{Hb}+\Delta \mathrm{HHb}\right)$ and oxidized cytochrome aa3 $(\Delta \mathrm{CtOx})$ in micromoles determined by Lambert-Beer's principle, tissue oxygenation or TOI (Tissue Oxygenation Index) is determined in percentage. The absorption spectrometer measures the difference in optical densities at sequential measuring times during four selective wavelengths in the near-infrared range (four laserdiodes: $\sim 760,820,850$ and $910 \mathrm{~nm}$ ).

Only absolute changes in chromophore can be determined (micromolar), however not the level (absolute concentration) at which these changes (positive or negative direction) occur. The measurement value is zero as long as no changes in chromophore concentration take place (27).

The INVOS 5100 Oximeter (Somanetics Corp., Troy, USA) was also used in various acupuncture studies (5-8). Here, regional cerebral oxygen saturation $\left(\mathrm{rSO}_{2}\right)$ was calculated in percent from the proportion of oxygenated and deoxygenated hemoglobin. Normal values lie between 60 and $80 \%$ (27).

Figure 6 shows the hypothetically supposed function curves of stimulus intensity dependent upon the supposed duration of treatment. This diagram gains in value due to the actually measured, specific cerebral data regarding the changes in $\mathrm{O}_{2} \mathrm{Hb}$ and $\mathrm{HHb}$ shown on the right. The trend of the $\mathrm{O}_{2} \mathrm{Hb}$ parameter monitored by NIRS during laserneedle stimulation is nearly plateau-like. During manual metal needle stimulation, however, the $\mathrm{O}_{2} \mathrm{Hb}$ curve shows a sharp increase and a sharp decrease back to a value higher than the initial level.This is also the case in other parameters [e.g. bispectral analysis (BIS) of the electroencephalogram (EEG)] $(6,7,28)$.

Summarizing studies (5-7,29-32) documented a total of 328 measurements on 88 healthy volunteers (50 females, 38 males) at a mean age of $25.7 \pm 4.0$ $(\overline{\mathrm{x}} \pm \mathrm{SD})$ years (19-38 years).

A maximum of seven acupoints in different measurement series (needle acupuncture and laserneedle acupuncture) were investigated on the volunteers. The acupuncture schemes include two acupoints from TCM: Zanzhu (UB.2; needling: vertical 0.5-0.8 cun) and Yuyao (Ex.3; needling: slanted $0.3-0.5 \mathrm{cun})$. In addition, two ear acupoints (eye and liver; needling: slanted 0.3 cun), two 


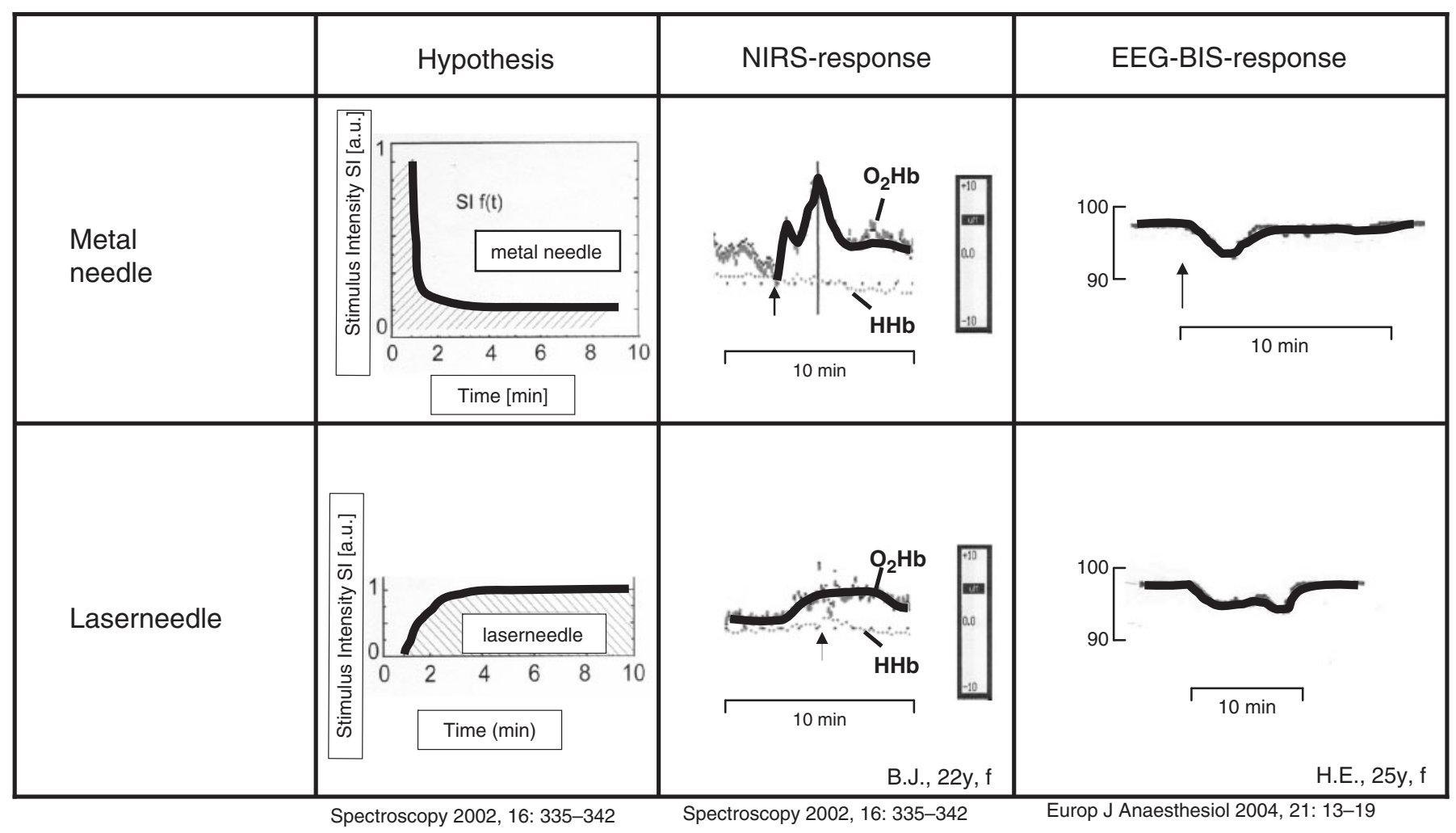

Figure 6. This diagram shows stimulus intensity as a function of time. On the left, the hypotheses and on the right side real measured cerebral responses of NIRS parameters and bioelectric responses are shown. Note the difference between the metal needle and laserneedle. Metal needle shows a short-term increase and laserneedle a continuous increase like a plateau. Modified from $(28,29)$.

specific eye acupoints according to Korean hand acupuncture (E2; needling: vertical 0.1-0.2 cun) and one acupoint from Chinese hand acupuncture (Yan Dian; needling: slanted 0.2 cun) were included in the study $(24,29)$.

In addition, possible responses in NIRS parameters resulting from needling and stimulation of a placebo point (location: lateral radius 6 cun above the horizontal fold at the wrist exactly on the radial edge, lateral from the lung meridian) were investigated. The different acupuncture schemes were applied alone or in combined manner, since preliminary studies showed different effects on measurement parameters dependent upon which acupoint combinations were selected (e.g. blood flow velocity in the ophthalmic artery) (6-8).

A $10 \mathrm{~min}$ resting period was made after applying the near-infrared sensors at the frontal area of the head. Then, either laserneedle stimulation was activated or acupuncture needles were applied and stimulated for $20 \mathrm{~s}$. Thereafter, all laserneedles were activated for $10 \mathrm{~min}$ or the needles were left undisturbed on the volunteer. During this time period, the maximum amplitude of $\Delta \mathrm{O}_{2} \mathrm{Hb}$ and $\triangle \mathrm{HHb}$ (phase during acupuncture) were analyzed. A control measurement (phase $5 \mathrm{~min}$ after acupuncture) was performed $5 \mathrm{~min}$ after deactivation or removal of the needles. Which technique was to be performed first and the sequence of stimulation (body, ear, hand and combination) was selected at random.
The resting period between each of the measurements was at least $30 \mathrm{~min}$.

Figure 7 shows the mean values of the maximum changes in parameter $\mathrm{O}_{2} \mathrm{Hb}$ during acupuncture and $5 \mathrm{~min}$ after manual needle acupuncture or laserneedle acupuncture.

Needling and stimulation of the placebo point did not lead to marked changes in cerebral NIRS parameters during or $5 \mathrm{~min}$ after acupuncture. The combination of Korean hand acupuncture (E2) and Chinese hand acupuncture (Yan Dian) as well as TCM body acupuncture [Zhanzhu (UB.2) and Yuyao (Ex.3)] and combined body, ear and hand acupuncture lead to a marked increase in $\mathrm{O}_{2} \mathrm{Hb}$ and a simultaneous decrease in $\mathrm{HHb}$. This effect is still present $5 \mathrm{~min}$ after removing the needles or deactivating laserneedle stimulation. One case of minimal contrary behavior in $\mathrm{O}_{2} \mathrm{Hb}$ and $\mathrm{HHb}$ is present when needling or performing laser stimulation at both ear points (eye and liver). Standard monitoring parameters such as blood pressure did not show any significant changes during all types of acupuncture or combined acupuncture methods.

\section{Functional Magnetic Resonance Imaging (fMRI)}

Functional magnetic resonance experiments are based on the indirect representation of neuronal activity and the 


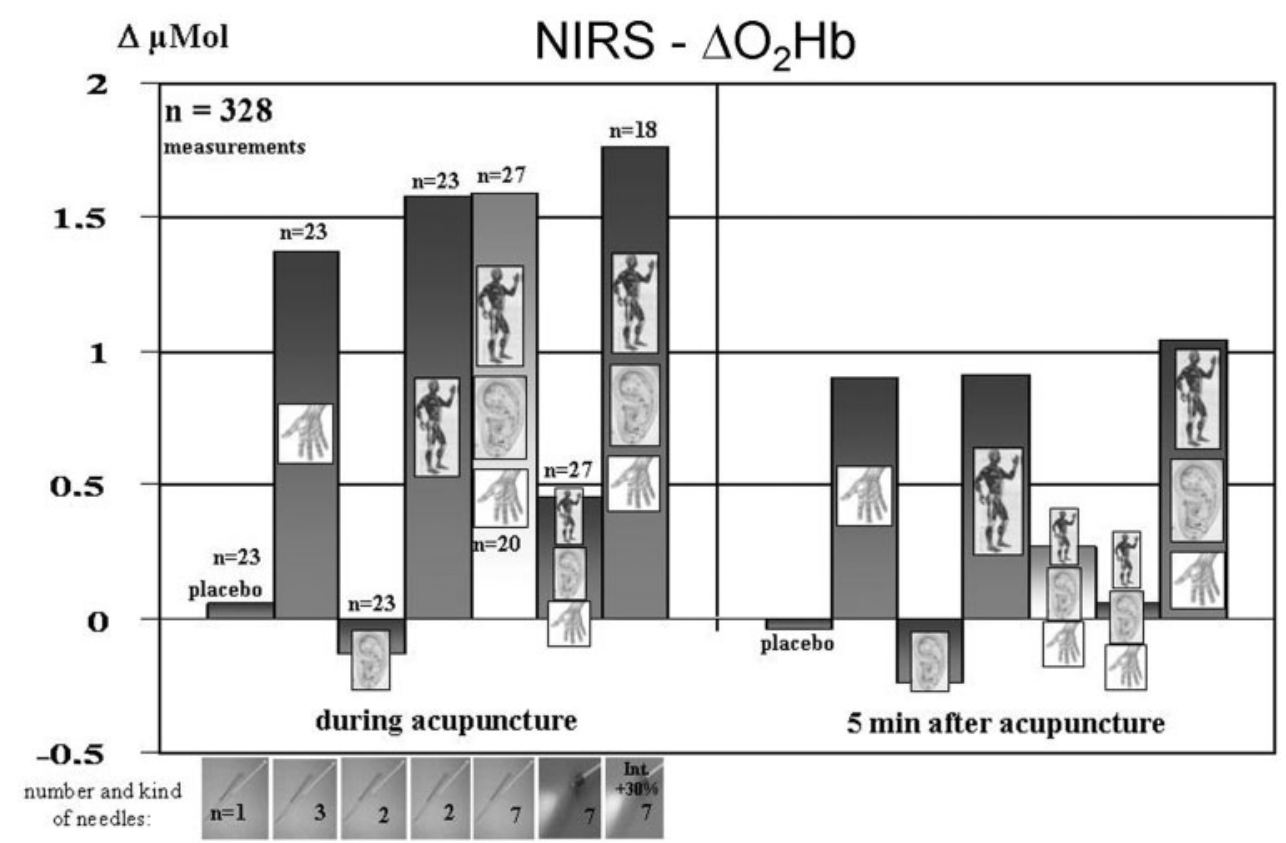

Figure 7. Changes of oxyhemoglobin in the sense of increases are demonstrated in this diagram. Modified from $(29,31,32)$.

resulting metabolic and circulatory changes, particularly the relative changes in concentration of oxygenated and deoxygenated hemoglobin. This method has been successfully used to investigate changes in cerebral activity during acupuncture (4). The fMRI for investigating laserneedle acupuncture has only been used in a few studies $(6,7,33)$. Based on the following observations some results should be shown exemplarily.

An acupuncture scheme comprising bilateral visual distant acupoints [Hegu (LI.4), Zusanli (St.36), Kunlun (UB.60), Zhiyin (UB.67)] was investigated (33).

The test persons were unable to determine whether the laserneedles were activated or deactivated during fMRI investigation. The fMRI study was based on a block design with alternating 2 min resting conditions (' $R$ ') and 2 min laserneedle activation ('A'). The experiment began with ' $R$ ' followed by the laserneedle condition ('A'). A total of three ' $R$ ' and three 'A' intervals were registered. Thus, each fMRI data recording period took $12 \mathrm{~min}$.

Functional MRI data was analyzed and evaluated with SPM 99 (Statistical Parametric Mapping) - software (SPM 99, Welcome Department of Imaging Neuroscience, London, England). All images from the test persons were newly arranged and the first picture was taken as reference using 'Sinc-interpolation'. Functional images were normalized spatially with a standard brain, thereafter they were smoothed with $6 \mathrm{~mm}$ GaussKernel (33).

The activated voxels were determined with a contrast between the activated condition and the resting condition. Changes under the level $P<0.05$ (correction for multiple comparisons with regard to the spatial extent of the performed activation) were considered to be significant. The activated regions were located using the Tailairach's atlas (33).

One result of the fMRI study showed significant changes in cerebral activity in the occipital and frontal regions during stimulation of visual acupoints (33).

\section{Bioelectrical Brain Function Methods}

Non-invasive bioelectrical neuromonitoring is gaining more and more attention in anesthesia and critical care. The bispectral index (BIS) is an important numerical descriptor of the EEG and is mainly used for assessing depth of anesthesia (28).

We found in healthy awake volunteers that acupressure at Yintang (Ex.1) results in statistically significant and clinically relevant reductions in BIS, while needle acupuncture, laserneedle acupuncture and acupressure at a control point result in statistically significant but clinically unimportant reductions (Fig. 8) (28). The results also highlight the electroencephalographic similarities of acupressure induced sedation and anesthesia $(6,7,28)$.

EEG entropy is also a new parameter that is used for quantification of depth of anesthesia. For the first time, the new method of entropy in EEGs was applied in an acupuncture study, and evidence regarding an acupuncture scheme consisting of 'sedative acupoints' compared to an acupuncture scheme that is considered to activate energy was validated (34). The study was conducted in a group of healthy volunteers $(n=9)$ to determine whether manual needle acupuncture and laser acupuncture stimulations applied to two groups of acupuncture 
Bispectral Index (BIS)


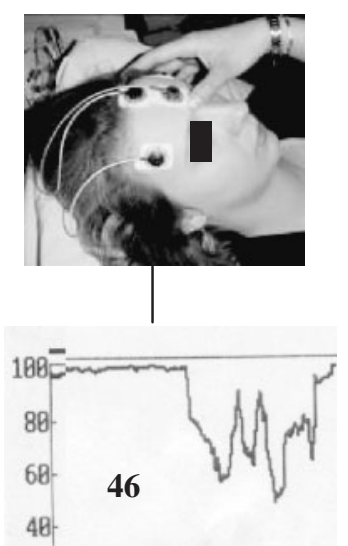
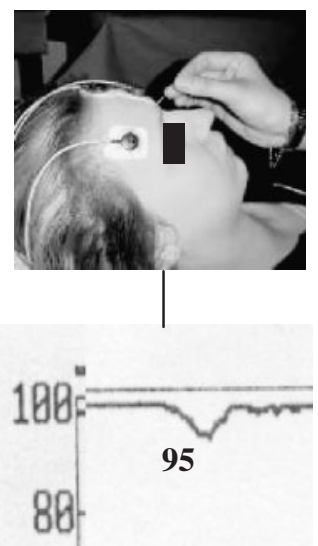
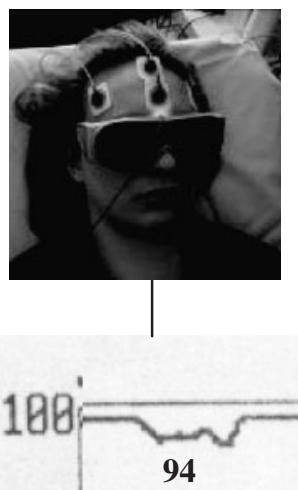

80
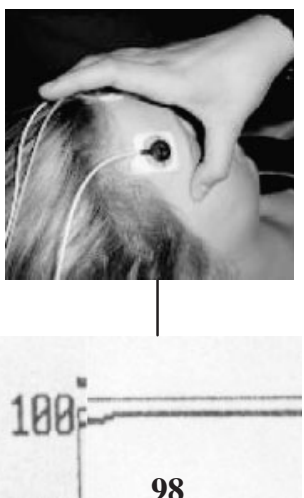

80.

Figure 8. Acupressure was performed at a control point (right) and the BIS showed values of about 98. Laserneedle acupuncture at Yintang resulted in BIS of 94. Needle acupuncture at Yintang showed BIS of 95. Acupressure at Yintang (left) reduced the BIS to a value of 46. Modified from (28).

Acupuncture scheme A

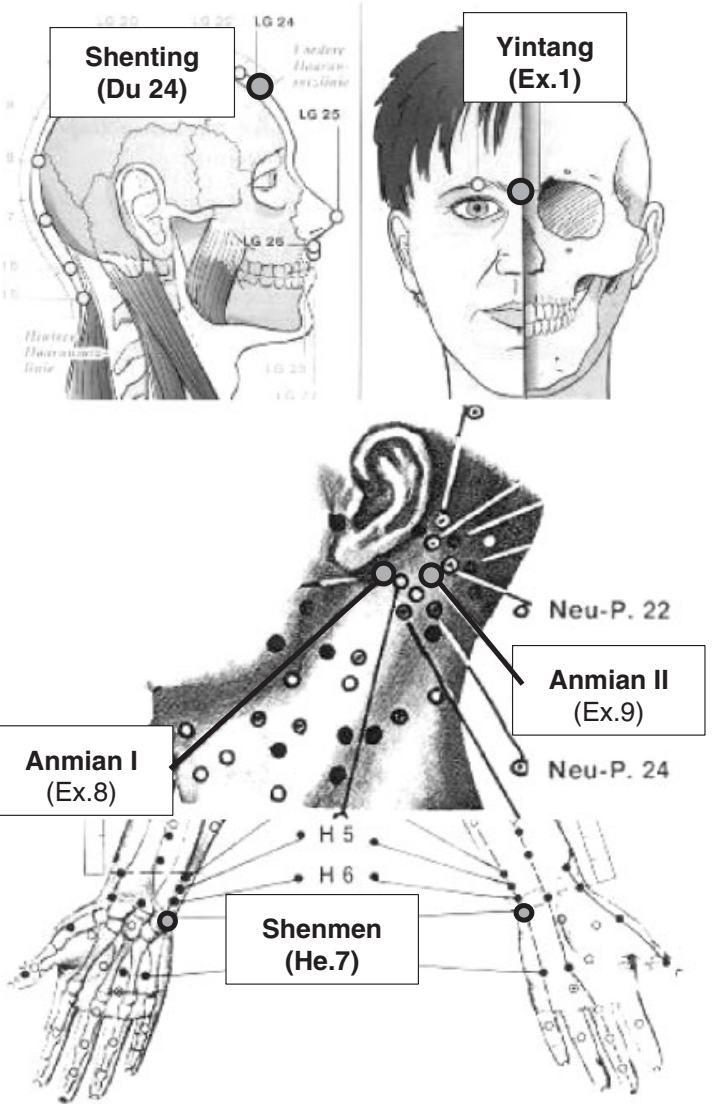

Acupuncture scheme B

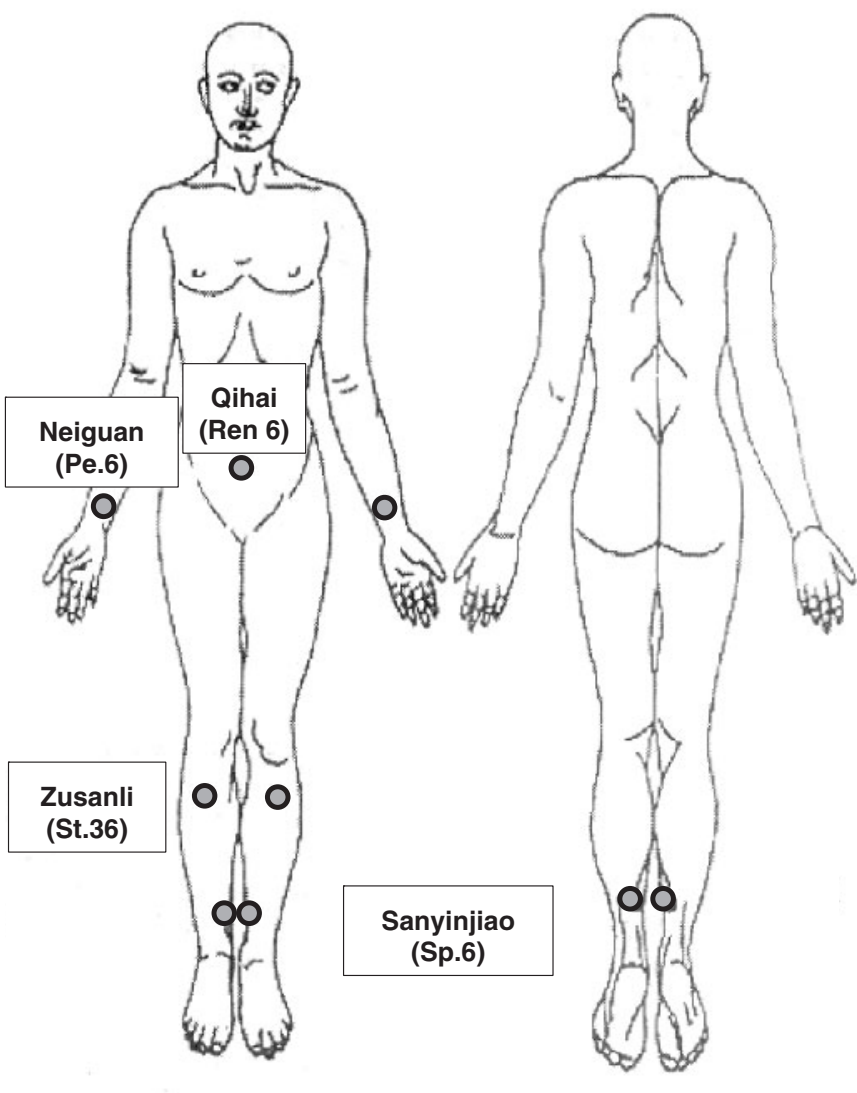

Figure 9. Two different acupuncture schemes were tested on different days on the same volunteer. The first scheme contained so-called sedative points and scheme B consisted of points, which according to TCM should support the general increase of Qi. Modified from (34). 




Figure 10. Box-plot illustration of entropy parameters showed no significant differences using scheme B. In contrast, the sedation scheme A induced significant reductions in both entropy parameters. Modified from (34).

points (sedative versus enhancement of energy) have effects on either state entropy (SE) or response entropy (RE) or both.

Two different acupuncture schemes were tested on different days using the same volunteer (Fig. 9). The first scheme (A) contained so-called sedative points and included the following acupuncture points in detail: Shenting (Du 24), Yintang (Ex.1), Sedative point 1 (Ex.8, Anmian I), Sedative point 2 (Ex.9, Anmian II) and Shenmen (He.7). Points Shenting and Yintang and their cerebral effects are described comprehensively in the scientific literature (35). Sedative point 1 is located at the median point of the connecting line between SJ 17 (Yi Feng) and Yi Ming (Ex.7). Sedative point 2 lies at the median point of the connection line between GB.20 (Feng Chi) and Yi Ming (Ex.7). The main indication for the latter two points is sleeplessness.

Scheme two (B) consists of points, which according to TCM should support the 'general availability of Qi-energy' (Fig. 9, right): Neiguan (Pe.6), Qihai (Ren 6), Zusanli (St.36) and Sanyinjiao (Sp.6). This scheme has been investigated by our study group a number of times and also leads to an increase in blood flow velocity of the MCA (6-8,15,17,19-22).

Measurement of entropy during needle and laserneedle acupuncture performed in this study showed that the brain plays a key role in acupuncture. Several preliminary investigations regarding this topic showed that acupressure can induce major effects in brain-specific neuromonitoring. For the first time, this study design could prove that two different acupuncture schemes can influence different parameters in the brain. The so-called 'sedation point scheme' (A) showed a significant decrease in both entropy parameters $(\mathrm{RE}+\mathrm{SE})$, which can be interpreted as a sedation effect in the EEG (Fig. 10). In the same volunteer, a different acupuncture scheme (B), which according to TCM leads to a general increase in Qi-energy, did not yield this effect. Moreover, several preliminary tests showed that the latter scheme leads to a significant increase in blood flow velocity in the MCA (17,19-22). In addition, this study (34) proves that laserneedle acupuncture is needle equivalent regarding 
the values of entropy described and has an important ranking as a painless method of acupuncture.

\section{Conclusion}

Bioengineering assessment of acupuncture can give evidence-based insight into different effects in the brain $(4-8,36)$. Although we have measured similar effects of needle and laserneedle acupuncture, it cannot be concluded that the results are based on the same basic mechanisms. Therefore, further studies would be necessary to investigate the anatomy and function structure of different acupoints and conducting pathways.

\section{Acknowledgements}

The author thanks Ms Lu Wang, MD LA for performing acupuncture and Ms Ingrid Gaischek, MSc for her valuable support in data registration and analysis (both Research Unit of Biomedical Engineering in Anesthesia and Intensive Care Medicine, Medical University of Graz). Some studies were supported partly by the Zukunftsfonds of the Styrian Government (project 4071).

\section{References}

1. Litscher G. Bioengineering assessment of acupuncture, part 1: thermography. Crit Rev Biomed Eng 2006;34:1-22.

2. Litscher G. Bioengineering assessment of acupuncture, part 2: monitoring of microcirculation. Crit Rev Biomed Eng 2006;34:273-94.

3. Litscher G. Bioengineering assessment of acupuncture, part 3: ultrasound. Crit Rev Biomed Eng 2006;34:295-326.

4. Litscher G. Bioengineering assessment of acupuncture, part 4: functional magnetic resonance imaging. Crit Rev Biomed Eng 2006;34:327-45.

5. Litscher G. Bioengineering assessment of acupuncture, part 5: cerebral near infrared spectroscopy. Crit Rev Biomed Eng 2006;34:439-57.

6. Litscher G, Schikora D. Laserneedle-acupuncture. Science and practice. Lengerich, Berlin, Bremen: Pabst Science Publishers, 2005.

7. Litscher G, Schikora D. Lasernadel-Akupunktur. Wissenschaft und Praxis. Lengerich, Berlin, Bremen: Pabst Science Publishers, 2004 (German).

8. Litscher G. Wissenschaftliche Grundlagen der Akupunktur. In: Bahr F, Bushe-Centmayer K, Dorfer L, Jost F, Litscher G, Suwanda S, et al (eds). Das große Buch der klassischen Akupunktur. Lehrbuch und Atlas. München: Elsevier Urban \& Fischer, 2006, 1-109 (German).

9. Bartels E. Color-coded duplex ultrasonography of the cerebral vessels. Atlas and manual. Stuttgart, New York: Schattauer, 1999.

10. Stöhr M, Riffel B, Pfadenhauer K. Neurophysiologische Untersuchungsmethoden in der Intensivmedizin. Berlin, Heidelberg: Springer, 1991 (German).

11. Marshall M. Praktische Doppler-Sonographie. 2. Auflage. Berlin, Heidelberg: Springer, 1996 (German).

12. Widder B. Doppler- und Duplexsonographie der hirnversorgenden Arterien. 5. Auflage. Berlin, Heidelberg: Springer, 1999 (German).

13. Litscher G, Yang NH, Schwarz G, Wang L. Computerkontrollierte Akupunktur: Eine neue Konstruktion zur simultanen und kontinuierlichen Erfassung der Blutflussgeschwindigkeit in der A. supratrochlearis und der A. cerebri media. Biomed Tech 1999; 44:58-63 (German) .

14. Litscher G, Wang L, Yang NH, Schwarz G. Ultrasound-monitored effects of acupuncture on brain and eye. Neurol Res 1999;21:373-7.
15. Litscher G, Cho ZH (eds). Computer-Controlled Acupuncture ${ }^{\circledR}$. Lengerich Berlin Düsseldorf Riga Scottsdale Wien Zagreb: Pabst Science Publishers, 2000.

16. Litscher G. A mulitifunctional helmet for noninvasive neuromonitoring. J Neurosurg Anesthesiol 1998;10:116-9.

17. Litscher G, Schwarz G, Sandner-Kiesling A, Hadolt I. Transkranielle Doppler-Sonographie - Robotergesteuerte Sonden zur Quantifizierung des Einflusses der Akupunktur. Biomed Tech 1997;42:116-22 (German).

18. Keller H, Baumgartner G, Regli F. Carotisstenosen und okklusionen. Diagnose durch perkutane Ultraschall-DopplerSonographie an der A. supraorbitalis oder A. supratrochlearis. Dtsch med Wschr 1973;98:1691-8 (German).

19. Litscher G. High-Tech Akupunktur ${ }^{\circledR}$. Lengerich Berlin Düsseldorf: Pabst Science Publishers, 2001 (German).

20. Litscher G, Schwarz G, Sandner-Kiesling A, Hadolt I, Eger E. Effects of acupuncture on the oxygenation of cerebral tissue. Neurol Res 1998;20 (Suppl 1):S28-32.

21. Litscher G, Schwarz G, Sandner-Kiesling A, Hadolt I. Robotic transcranial Doppler sonography probes, \& acupuncture. Int $J$ Neurosci 1998;95:1-15.

22. Litscher G, Wang L, Yang NH, Schwarz G. Computer-controlled acupuncture. Quantification and separation of specific effects. Neurol Res 1999;21:530-4.

23. Litscher G, Schikora D. Neue Konzepte in der experimentellen Akupunkturforschung - computerkontrollierte Laserpunktur (CCL) mit der Laserneedle-technik. Europ Ztschr $f$ Akupunktur. Der Akupunkturarzt/Aurikulotherapeut 2002;3:18-27 (German).

24. Litscher G. Computer-based quantification of traditional chinese-, ear- and Korean hand acupuncture: needle-induced changes of regional cerebral blood flow velocity. Neurol Res 2002;24:377-80.

25. König G, Wancura I. Neue Chinesische Akupunktur. Lehrbuch und Atlas der Akupunkturpunkte. Wien München Bern: Wilhelm Maudrich, 1989 (German).

26. Yoo TW. Koryo hand therapy - Korean hand acupuncture. Seoul: Eum Yang Mek Jin Publishing Co, 2001.

27. Litscher G, Schwarz G (eds). Transcranial cerebral oximetry. Lengerich Berlin Düsseldorf Riga Scottsdale (USA) Wien Zagreb: Pabst Science Publishers, 1997.

28. Litscher G. Effects of acupressure, manual acupuncture, \& laserneedle acupuncture on EEG bispectral index (BIS) and spectral edge frequency (SEF) in healthy volunteers. Europ $J$ Anaesthesiol 2004;21:13-9.

29. Litscher G, Schikora D. Near-infrared spectroscopy for objectifying cerebral effects of needle and laserneedle acupuncture. Spectroscopy 2002;16:335-42.

30. Litscher G, Schikora D. Nahinfrarot-spektroskopische Untersuchungen zur Nadel- und Lasernadelakupunktur. $A K U$ Akupunktur Theorie und Praxis 2002;3:140-6 (German).

31. Litscher G. NIR spectroscopy explores the mysteries of acupuncture. Spectroscopy Europe 2005;17:8-14.

32. Litscher G. NIR spectroscopy explores the mysteries of acupuncture. Spectroscopy Asia 2005;1:8-14.

33. Litscher G, Rachbauer D, Ropele S, Wang L, Schikora D, Fazekas F, et al. Acupuncture using laser needles modulates brain function: first evidence from functional transcranial Doppler sonography and functional magnetic resonance imaging. Lasers Med Sci 2004;19:6-11.

34. Litscher G. Electroencephalogram-entropy and acupuncture. Anesth Analg 2006;102:1745-51.

35. Litscher G. Shenting and Yintang: quantification of cerebral effects of acupressure, manual acupuncture, and laserneedle acupuncture using high-tech neuromonitoring methods. Med Acup 2005;16:24-9.

36. Lewith GT, White PJ, Pariente J. Investigating acupuncture using brain imaging techniques: the current state of play. Evid Based Complement Alternat Med 2005;2:315-9.

37. Litscher G. Bioengineering assessment of acupuncture, part 6: Monitoring- Neurophysiology. Crit Rev Biomed Eng 2007;35:1-39.

Received April 23, 2007; accepted September 6, 2007 


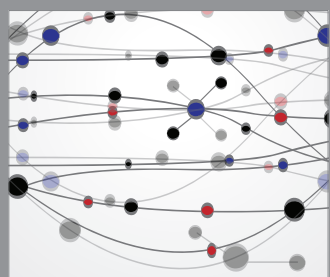

The Scientific World Journal
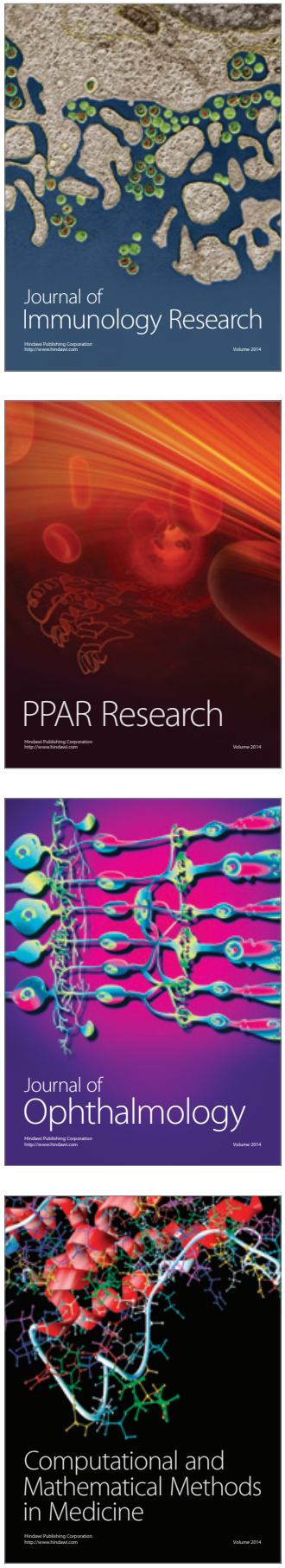

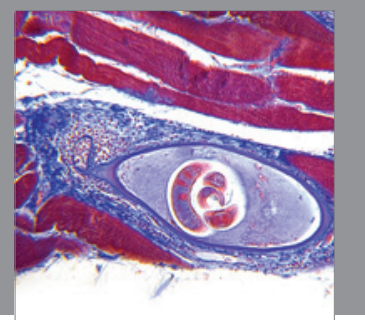

Gastroenterology

Research and Practice
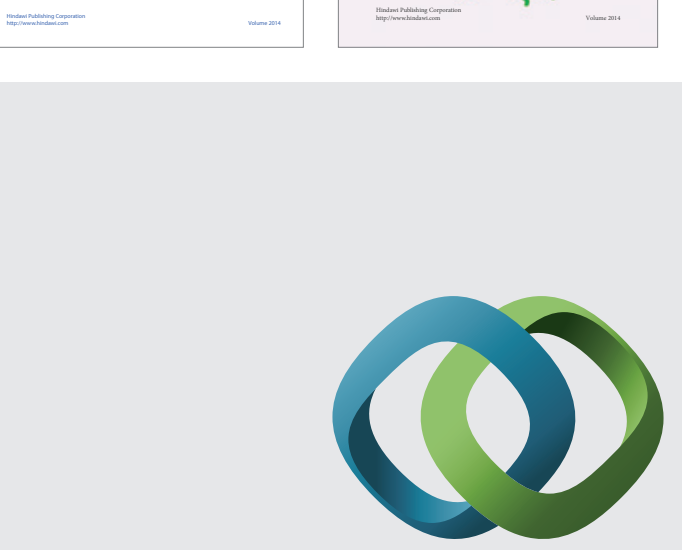

\section{Hindawi}

Submit your manuscripts at

http://www.hindawi.com
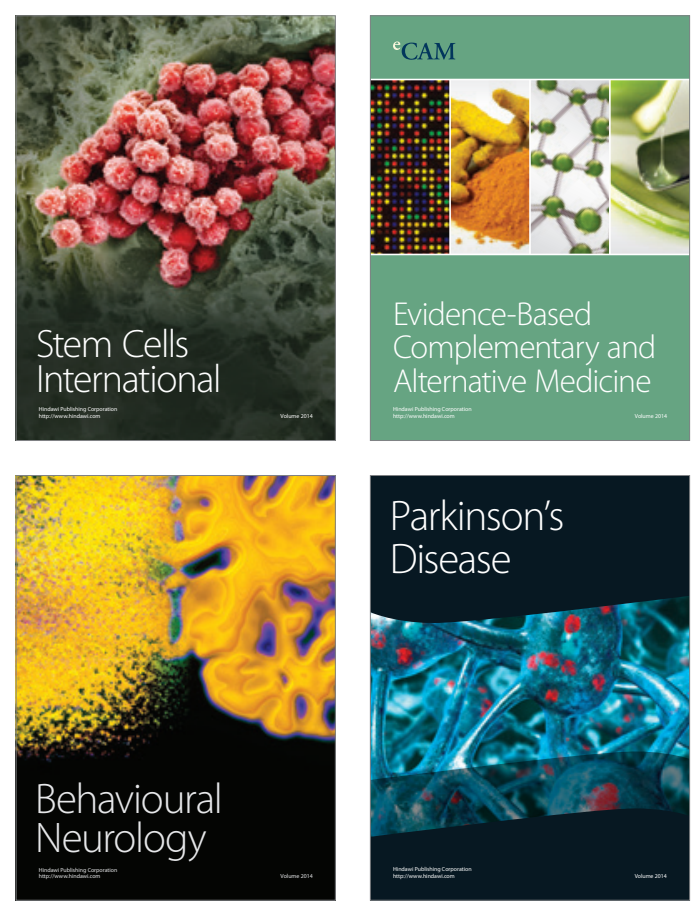



Journal of
Diabetes Research

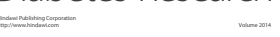

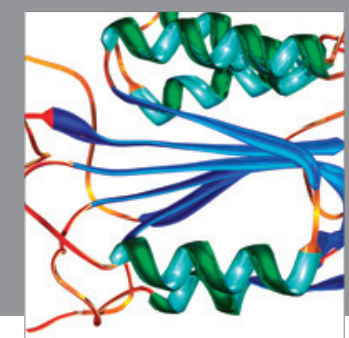

Disease Markers
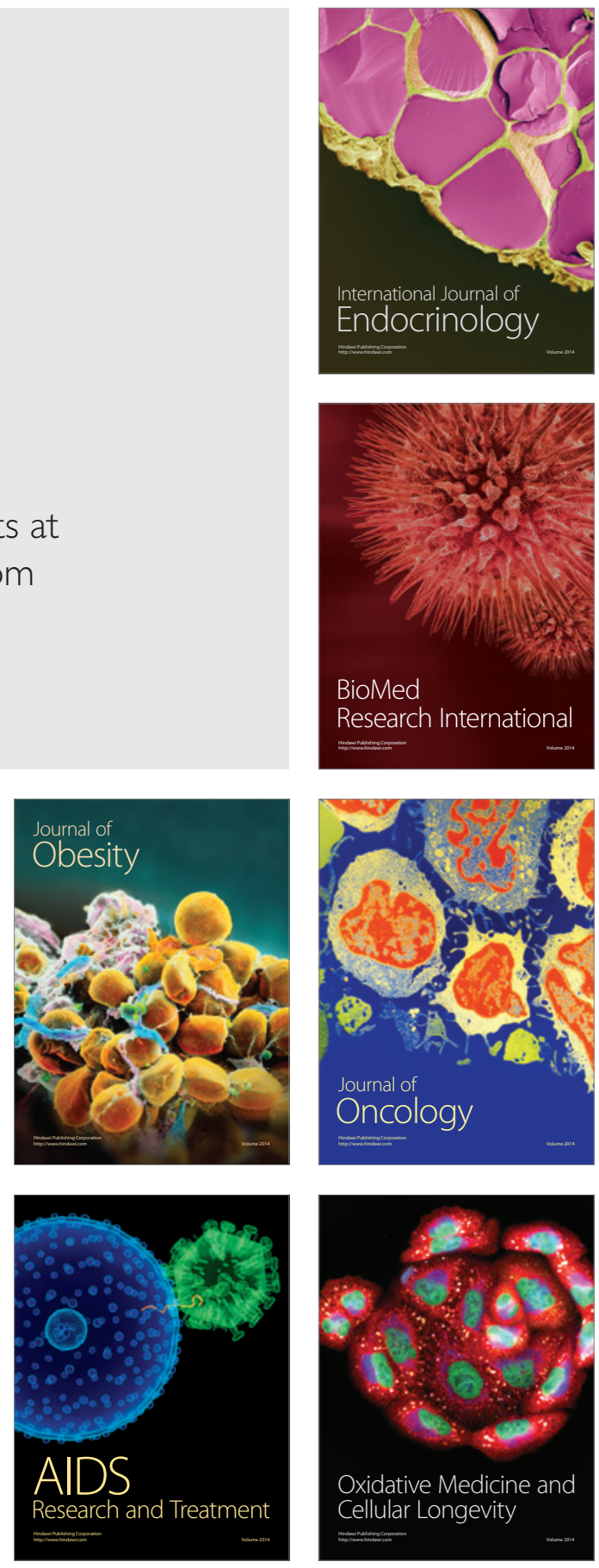